\title{
Crescimento sob restrição externa: evidências empíricas para países de renda baixa no contexto do boom dos preços internacionais das commodities (2000-2014).
}

Growth under external restrictions: empirical evidence for low-income countries in the context of the boom in international commodity prices (2000-2014).

\section{Henrique Rogê Batista*}

\begin{abstract}
Resumo
Este trabalho sustenta-se sob a literatura pós-Keynesiana, a aplicação da Lei de Thirlwall Multissetorial (2007), para testar, numa amostra de 19 países de renda baixa, se o balanço de pagamentos restringe o crescimento da amostra agregada. $\bigcirc$ período selecionado para análise visa captar o momento de boom dos preços internacionais das commodities que, tendo em vista a composição da pauta exportadora por intensidade tecnológica destes países, majoritariamente de produtos primários e de baixa intensidade tecnológica, tende a beneficiar seus termos de troca. Além da validade da lei testada, os resultados indicam que os ganhos com a elevação dos preços das commodities são diluídos dado o volume importado nos setores de maior intensidade tecnológica e, inclusive, de commodities.
\end{abstract}

Palavras-chave: Lei de Thirlwall Multissetorial; Crescimento Econômico; Restrição Externa.

Classificação JEL: F14; F40; 041

\begin{abstract}
The present work is supported by post-Keynesian literature, applying the Thirlwall Multisectoral Law (2007), to test, in a sample of 19 low-income countries, whether balance of payments restricts the growth of the aggregated sample. The period selected for analysis aims to capture the boom in international commodity prices, which, given the composition of the exporting tariff by technological intensity of these countries, mainly primary products and with low technological intensity, tends to benefit their trading terms. In addition to the validity of the tested law, the results indicate that gains from rising commodity prices are diluted given the volume imported into the most technologically intensive and, even, commodity sectors.
\end{abstract}

Keywords: Economic Growth; External Constraint; Thirlwall Law; Multisectoral. JEL Classification: F14; F40; $\bigcirc 41$.

Professor Adjunto da Universidade Federal do Mato Grosso (UFMT). E-mail: henriqueroge@hotmail.com 


\section{Introdução}

A literatura empírica que aborda o comportamento relativo do crescimento econômico tem observado o distanciamento entre a renda dos países pobres com a dos ricos (Catela e Porcile, 2010). Isto se deve, sobretudo, aos entraves com que parte de tais países de renda baixa se deparam, associados a diferentes fatores de ordem econômica, social e demográfica, e que ofertam resistência ao alcance e manutenção de taxas de crescimento positivas. Em suma, este conjunto de entraves e seus desdobramentos sobre o crescimento econômico guardam contradições de natureza empírica e teórica (Im e Rosenblatt, 2013).

Este trabalho baseia-se em Dutt (2015) e Thirlwall e Pacheco (2008), os quais atribuem à estrutura produtiva - mudança estrutural - as diferenças de crescimento entre os países. Nesta ótica, destaca-se que os países com reduzida renda per capita apresentam, predominantemente, produção agrícola e de baixa intensidade tecnológica, o que reflete na sua composição setorial do comércio internacional (Tho, 2013; Eichengreen, Park, e Shin, 2013).

Considerando a especificidade desses países, a composição setorial no comércio internacional e a resistência na manutenção do crescimento econômico, o presente trabalho abordará a literatura pós-Keynesiana para explorar as especificidades do crescimento de tais países ${ }^{1}$. Para isto, apoia-se na Lei de Thirlwall (LT) (ver Thirwall, 1979), que tem sido intensamente utilizada na literatura voltada ao crescimento econômico. Em suma, a LT parte do contexto do crescimento determinado pelas condições de demanda, cujas elasticidades-renda das exportações e das importações permitem estimar a taxa de crescimento compatível com o equilíbrio do balanço de pagamentos a longo prazo.

Dos diversos modelos que se desdobraram da versão original de 1979, o modelo de Araújo e Lima (2007) se destaca por expandir a análise para o ponto de vista multissetorial, modelo denominado como Lei de Thirlwall Multissetorial (LTM). Em termos gerais, os resultados empíricos obtidos a partir da LTM corroboram a validade da lei e destacam a composição setorial das exportações e importações para a determinação da restrição externa das economias, bem como da possibilidade de identificação dos setores que apresentam maior potencial para a elevação da demanda (Da Silva, Santos, Baptista, 2017).

Aqui, Thirlwall (2011) reconhece que a LTM tem um poder de predição maior do que a da LT agregada para esses países em desenvolvimento: "(..) the multi-

\footnotetext{
${ }^{1}$ Especificamente a que analisa a variação da renda sujeita às limitações impostas pelo balanço de pagamentos do ponto de vista setorial por intensidade tecnológica.
} 
sectoral model has a higher predicted error than the aggregate model, but for both groups of countries the mean absolute error is lower for the multi-sectoral model. Then for this group of countries, it has a better fit than the aggregated TL" (Thirlwall, 2011, p. 332).

Esta abordagem é particularmente interessante aos países emergentes e em desenvolvimento, uma vez que a LTM capta mudanças estruturais em andamento e os seus respectivos desdobramentos no tempo sobre a taxa de crescimento de equilíbrio no Balanço de Pagamentos. Daí deriva a relevância da composição do comércio internacional e a justificativa da LTM ser especialmente aplicável a tais países, tendo em vista que a mudança estrutural é uma característica relevante do seu crescimento (Blecker e Setterfield, 2019).

A mudança estrutural tratada aqui se refere às especializações na composição da pauta exportadora e importadora, tendo em vista que a maior parte das exportações manufaturadas tem elasticidades-renda mais altas em relação às mercadorias primárias (Carbinato, 2010; Romero et al. 2011). Isto se deve ao fato de a taxa de crescimento da demanda mundial ser diferente entre os setores. Logo, o crescimento de longo prazo depende, então, da capacidade das economias de ingressar nos mercados com mais alta elasticidade-renda da demanda (Cimoli et al, 2005).

Neste contexto, na ótica da mudança estrutural, enquanto a composição das exportações e importações são consideradas variáveis no tempo, se presume que as elasticidades da renda sejam características mais ou menos permanentes dos produtos aos quais eles pertencem (Blecker e Setterfield, 2019). Aqui, cabe ressaltar que a variação internacional nos preços pode inferir sobre os termos de troca que, por sua vez, inferem nas restrições ao crescimento (Bassos, 2014). Assim, dada a composição do balanço comercial, eventuais momentos favoráveis às exportações, em termos de preços internacionais, podem ser mitigados quando o share das importações por bens, cuja demanda seja sensível à renda, é elevado ou quando o dispêndio com as importações também é favorecido pelos preços internacionais (Gouvêa, 2010; Batista e Neder, 2020).

Tendo isto em vista, este estudo testará se a restrição externa se configura enquanto um entrave ao crescimento dos países de renda baixa, estimando as elasticidades-renda da demanda. Com este fim, será explorada a composição e evolução setorial das pautas exportadora e importadora, tomando a variação dos preços das commodities internacionais. $O$ período abordado compreende o intervalo 
entre 2000 e 2014 para uma amostra de 19 países $^{2}$. $\bigcirc$ período selecionado busca captar o boom dos preços internacionais das commodities que corresponde a uma parcela significante do balanço comercial da amostra e, consequentemente, infere sobre os termos de troca. Cabe justificar, salvo poucas exceções, que a composição da pauta comercial apresenta uma dinâmica não muito destoante entre as unidades de observação em termos da composição tecnológica, o que justifica a agregação para estimar as elasticidades da LTM.

Desta forma, este trabalho aborda uma amostra ainda pouco explorada pela teoria pós-Keynesiana da restrição do balanço de pagamentos; além disto, adota um recorte temporal estratégico, voltando a atenção aos termos de troca e à estrutura comercial da amostra. Assim, sua contribuição se dá ao explorar a relevância dos preços favoráveis dos exportáveis, ao compensar uma estrutura produtiva e comercial focada em bens de baixo conteúdo tecnológico na restrição externa do crescimento. Portanto, este estudo sublinha as especificidades do crescimento dos países de renda baixa, desdobrando a relevância da administração da pauta exportadora e importadora.

Este artigo encontra-se dividido em três partes, além desta introdução. $\mathrm{Na}$ segunda seção é apresentada a LTM do ponto de vista algébrico e algumas evidências empíricas. A terceira seção traz a descrição dos dados utilizados, que inclui sua fonte e tratamento estatístico, e a metodologia de dados em painel. A quarta seção destaca os principais resultados encontrados para, posteriormente, serem sublinhadas as principais conclusões.

\section{Lei de Thirlwall Multissetorial}

Os modelos de Pasinetti $(1981,1993)$ e a LT na sua versão original são os pilares da formalização da LTM. Em Pasinetti (1981, 1993), o crescimento agregado da economia pode ser entendido a partir da demanda, onde o desempenho dos distintos setores da economia é relevante a partir de suas respectivas mudanças estruturais. Logo, em termos de crescimento, do ponto de vista da LT, a LTM toma a restrição no balanço de pagamento e, em Pasinetti (1981, 1993), a estrutura produtiva.

Para a formalização do modelo, Araújo e Lima (2007) partem da existência do país A (avançado) e do país $U$ (em desenvolvimento), ambos produzindo $n-1$ bens de consumo, com $i=1,2, \ldots, n-1$. Para o fluxo de mercadoria e monetário do país

2 Foram excluídos da amostra aqueles países cuja quantidade de missing entre as variáveis selecionadas foi elevada suficientemente para comprometer as estimativas e conclusões deste trabalho. 
U, são considerados três pressupostos: a condição de pleno emprego, a condição de pleno dispêndio da renda, e o equilíbrio do balanço de pagamentos.

Pela condição de pleno emprego, temos:

$$
\sum_{i=1}^{n-1}\left(a_{i n}+\zeta a_{i \hat{n}}\right) a_{n i}=1
$$

Onde: $a_{i n}$ é o coeficiente de demanda per capita doméstica; $a_{i n \hat{n}}$ ó o coeficiente de demanda per capita externa; $a_{n i}$ é o coeficiente que representa a quantidade de trabalho empregada em cada setor i; $\hat{n}$ é o setor de famílias no país A e; $\zeta$ é o coeficiente de proporcionalidade entre a população de ambos os países.

Tomando a condição de pleno dispêndio da renda nacional, temos:

$$
\sum_{i=1}^{n-1}\left(a_{i n}+a_{i n}\right) a_{n i}=1
$$

Onde, $a_{\text {in }}$ é o coeficiente da demanda per capita por importações do bem de consumo i produzido pelo país A.

Aqui, o equilíbrio do Balanço de Pagamentos é dado pelos coeficientes de trabalho:

$$
\sum_{i=1}^{n-1}\left(\zeta a_{i \hat{n}}+a_{\hat{\imath} n}\right) a_{n i}=0
$$

A solução do sistema parte da consideração de que a quantidade total do bem comercializável produzido é dada pela soma das demandas doméstica e externa do bem considerado:

$$
X_{i}=\left(a_{i n}+\zeta a_{i \hat{n}}\right) X_{n}, i=1,2, \ldots, n-1
$$

Onde $X_{i}$ é a quantidade produzida do bem i e $X_{n}$ é a população, ambos do país $U$.

Seja, respectivamente, $p_{i}$ e $w_{u}$ o preço da mercadoria i e a taxa de salário no país $U$, o conjunto de solução para o preço é dado por:

$$
p_{i}=a_{n i} w_{u}, i=1,2, \ldots, n-1
$$

Então, a vantagem comparativa na produção do bem i passa a ser dada pelo preço relativo deste bem entre os países A e U. Desta forma, quando $p_{\hat{\imath}}>p_{i}$, a 
demanda externa pelo bem i passa a ser representada pela função de exportação. A demanda externa do bem i pode ser representada como:

$$
x_{i \hat{n}}=\left\{\begin{array}{ccc}
0 & \text { se } & p_{\hat{\imath}}<p_{i} \\
\left(\frac{p_{i}}{\hat{p}_{i}}\right)^{\eta_{i}} Y_{A}^{\beta_{i}}, & \text { se } & p_{\hat{\imath}} \geq p_{i}
\end{array}\right.
$$

Onde: $\hat{x}_{i n}$ é a demanda externa pelo bem i; $\eta_{i}$ é a elasticidade-preço da demanda por exportações do bem i $\left(\eta_{i}<0\right)$; $\beta_{i}$ é a elasticidade-renda da demanda por exportações; e $Y_{A}$ é a renda nacional do país A.

Então, o coeficiente per capita da demanda externa pela mercadoria i pode ser representado como:

$$
a_{i \hat{n}}=\left\{\begin{array}{lrc}
0, & \text { se } & \hat{p}_{i}<p_{i} \\
\left(\frac{p_{i}}{p_{\hat{\imath}}}\right)^{\eta_{i}} y_{A}^{\beta_{i}} X_{\hat{n}}^{\beta_{i}-1}, & \text { se } \hat{p}_{i} \geq p_{i}
\end{array}\right.
$$

Do ponto de vista das importações, o raciocínio é análogo: se $p_{i}>p_{\hat{\imath}}$, tem-se a função de demanda por importação do bem i e o coeficiente de importação deste bem pode ser expresso como:

$$
a_{\hat{\imath} n}= \begin{cases}0, & \text { se } \quad p_{i}<p_{\hat{\imath}} \\ \left(\frac{p_{\hat{\imath}}}{p_{i}}\right)^{\Psi_{i}} Y_{U}^{\varphi_{i}} X_{n}^{\varphi_{i}-1}, & \text { se } p_{i} \geq p_{\hat{\imath}}\end{cases}
$$

Onde: $\Psi_{i}$ é a elasticidade preço da demanda por importações do bem i; $\varphi_{i}$ é a elasticidade renda da demanda por importações e; $Y_{u}$ a renda real do país U. As taxas de crescimento per capita da demanda por exportações e importações do bem i são resultadas ao aplicar o logaritmo natural e diferenciando em relação ao tempo. Respectivamente, tais taxas são representadas como ${ }^{3}$ :

$$
\begin{aligned}
& \frac{\dot{a}_{i \hat{n}}}{a_{i \hat{n}}}=\left\{\begin{array}{c}
0, \quad \text { se } p_{\hat{\imath}}<p_{i} \\
\eta_{i}\left(\sigma_{i}^{U}-\sigma_{i}^{A}\right)+\beta_{i} \sigma_{y}^{A}+\left(\beta_{i}-1\right) \hat{g}, \text { se } p_{\hat{\imath}} \geq p_{i}
\end{array}\right. \\
& \frac{\dot{a}_{\hat{\imath} n}}{a_{\hat{\imath} n}}=\left\{\begin{array}{c}
0, \quad \text { se } \quad p_{i}<p_{\hat{\imath}} \\
\Psi_{i}\left(\sigma_{i}^{A}-\sigma_{i}^{U}\right)+\varphi_{i} \sigma_{y}^{U}+\left(\varphi_{i}-1\right) g, \text { se } p_{i} \geq p_{\hat{\imath}}
\end{array}\right.
\end{aligned}
$$

As taxas de crescimento per capita da demanda externa e por importações podem ser respectivamente reescritas como:

\footnotetext{
${ }^{3}$ Para as exportações são satisfeitas: $\frac{\dot{p}_{\imath}}{p_{i}}=\sigma_{i}^{U}, \frac{\dot{p}_{i}}{p_{\hat{\imath}}}=\sigma_{i}^{A}, \frac{\dot{y}_{A}}{y_{A}}=\sigma_{y}^{A}$ e $\frac{\dot{X}_{\hat{n}}}{\hat{X}_{\hat{n}}}=\hat{g}$; para as importações: $\frac{\dot{y}_{U}}{y_{U}}=\sigma_{y}^{U}$ $\mathrm{e} \frac{\dot{X}_{n}}{X_{n}}=g$.
} 


$$
\begin{aligned}
& \frac{\dot{a}_{i \hat{n}}}{a_{i \hat{n}}}=\beta_{i} \sigma_{y}^{A} \\
& \frac{\dot{a}_{\hat{\imath} n}}{a_{\hat{\imath} n}}=\varphi_{i} \sigma_{y}^{U}
\end{aligned}
$$

Para isto, tomamos que a taxa de variação do preço do bem i seja igual entre os países, ou seja, $\sigma_{y}^{A}=\sigma_{y}^{U}$, e que $g=\hat{g}=0$, isto garante que a população entre ambos os países seja constante.

Resgatando o terceiro pressuposto, o equilíbrio na balança de pagamentos, a taxa de variação da Equação 3 é igual a zero, então:

$$
\sum_{i=1}^{n-1}\left(\zeta \dot{a}_{i \hat{n}}-\dot{a}_{\hat{\imath} n}\right) a_{n i}+\sum_{i=1}^{n-1}\left(\zeta a_{i \hat{n}}-a_{\hat{\imath} n}\right) a_{n i}=0
$$

Como o modelo desconsidera a existência de progresso tecnológico, $\dot{a}_{i n}(t)=$ 0, a Equação 13 é reescrita como:

$$
\sum_{i=1}^{n-1}\left(\zeta \dot{a}_{i \hat{n}}-\dot{a}_{\hat{\imath} n}\right) a_{n i}=0
$$

Substituindo as Equações 11 e 12 na Equação 14:

$$
\sigma_{y}^{U}=\frac{\sum_{i=1}^{n-1} \xi \beta_{i} a_{i \hat{n}} a_{n i}}{\sum_{i=1}^{n-1} \varphi_{i} a_{\hat{\imath} n} a_{n i}} \sigma_{y}^{A}
$$

A partir da Equação 11, temos que:

$$
\sigma_{y}^{A}=\frac{\sum_{i=1}^{n-1} \frac{\dot{a}_{i \hat{n}}}{a_{i \hat{n}}}}{\sum_{i=1}^{n-1} \beta_{i}}
$$

Substituindo a Equação 16 na Equação 15:

$$
\sigma_{y}^{U}=\frac{\sum_{i=1}^{n-1} \xi \beta_{i} a_{i \hat{n}} a_{n i}}{\left(\sum_{i=1}^{n-1} \varphi_{i} a_{\hat{i} n} a_{n i}\right)\left(\sum_{i=1}^{n-1} \beta_{i}\right)} \sum_{i=1}^{n-1} \frac{\dot{a}_{i \hat{n}}}{a_{i \hat{n}}}
$$

Nesta versão multissetorial (Equação 17), a taxa de crescimento per capita do país $U$ é representada por $\sigma_{y}^{U}$. Pode-se observar que, na composição da demanda, importações e exportações, as elasticidades setoriais são relevantes para determinar o crescimento das unidades de observação. Isto permite afirmar que, mesmo diante da ausência da variação positiva da renda do resto do mundo, as unidades de observação podem elevar a taxa de crescimento da renda, gerenciando a composição 
setorial do balanço comercial e, neste caso, mantendo as elasticidades-renda da demanda. Ou seja, a taxa de crescimento pode variar de acordo com políticas que promovem as exportações nos setores que apresentam maiores elasticidades-renda e reduzem a importação, também, nos setores de maior elasticidade-renda (Thirlwall, 2011). Portanto, o crescimento com equilíbrio no balanço de pagamentos está condicionado às elasticidades-renda do comércio exterior e da composição setorial da pauta comercial (Soares e Teixeira, 2012).

A bibliografia empírica tem apontado os setores de maior intensidade tecnológica como sendo aqueles que apresentam maiores elasticidades-renda, reforçando a questão setorial para o crescimento (Gouveia e Lima, 2009; Carbinato, 2010; Queiroz et al., 2011; Soares e Teixeira, 2012). Romero e McCombie (2016) chamam a atenção para a validade e a convergência das evidências empíricas da LTM na bibliográfica econômica.

A Tabela 1 traz a síntese de alguns trabalhos empíricos da LTM. Como podese observar, a técnica de agregação para a aplicação da metodologia de Dados em Painel, proposta neste trabalho, já foi empregada na literatura. Entretanto, segundo este levantamento, a análise para o grupo de países pobres com o recorte temporal que capta a elevação dos preços internacionais das commodities não foi encontrada. Isso fomenta a indagação levantada na introdução, que questiona a existência de restrição externa, mesmo no contexto dos preços exportáveis favoráveis aos países de renda baixa.

A alteração da composição setorial das importações e exportações é um elemento relevante para explicar a tendência de elevação da renda nos países subdesenvolvidos e foi importante para compreender a convergência de renda para patamares de renda mais elevados (Cimoli, Porcile e Rovira, 2010).

Apesar das críticas que assolam a LT e suas derivações ${ }^{4}$, McCombie (2011) reconhece a relevância dos modelos de crescimento restritos pelo balanço de pagamentos ao explicar as diferentes taxas de crescimento na economia. Cimoli, Porcile e Rovira (2010), adicionalmente, destacam as mudanças estruturais que historicamente foram relevantes para os países em desenvolvimento ao apresentarem tendências de convergência para patamares de renda mais elevados. Isso seria resultado, dentre outros fatores, da ampliação das exportações naqueles setores que apresentam maiores elasticidades-renda relativas às importações, também, dos setores de maior elasticidade renda.

${ }^{4}$ Ver McCombie (2011). 
Tabela 1. Revisão empírica da LTM

\begin{tabular}{|c|c|c|}
\hline Artigo & Amostra (Período), Método & Principais conclusões em relação à LTM \\
\hline $\begin{array}{l}\text { Gouvêa e } \\
\text { Lima (2009) }\end{array}$ & $\begin{array}{l}\text { Brasil (1962-2006), } \\
\text { Vetor de correlação de erro (VEC) }\end{array}$ & $\begin{array}{l}\text { i) no período analisado a restrição externa } \\
\text { exerceu e foi importante ao explicar o } \\
\text { crescimento da economia brasileira; ii) de } 1962 \\
\text { a } 1965 \text { elevou a relação entre as elasticidades- } \\
\text { renda da exportação e da importação, dado a } \\
\text { alteração estrutural do comercio, de modo a } \\
\text { reduzir a restrição externa do país; tal processo } \\
\text { é revertido pós-1965. }\end{array}$ \\
\hline $\begin{array}{l}\text { Gouvêa } \\
(2010)\end{array}$ & $\begin{array}{c}90 \text { países (1962-1999), Dados em } \\
\text { Painel pelo método de Efeitos } \\
\text { Fixos (EF) }\end{array}$ & $\begin{array}{l}\text { i) as elasticidades-renda das exportações e } \\
\text { importações para os setores primários são } \\
\text { menores, relativos aos demais setores. ii) } \\
\text { validade da LTM; iii) dados os valores das } \\
\text { elasticidades, a composição setorial das } \\
\text { exportações e importações é relevante na } \\
\text { determinação da restrição externa das } \\
\text { economias. }\end{array}$ \\
\hline $\begin{array}{l}\text { Carbinato } \\
(2010)\end{array}$ & $\begin{array}{l}\text { Brasil (1962-2006), VEC e } \\
\text { Ordinary Least Squares (OLS) }\end{array}$ & $\begin{array}{l}\text { i) os setores de maior intensidade tecnológica } \\
\text { apresentam maiores elasticidades-renda e } \\
\text { participação relativa no comércio } \\
\text { internacional; ii) o perfil setorial do comércio } \\
\text { internacional é relevante para o crescimento } \\
\text { econômico de longo prazo; iii) diferentes } \\
\text { composições setoriais resultam em diferentes } \\
\text { taxas de crescimento de longo prazo. }\end{array}$ \\
\hline $\begin{array}{l}\text { Romero et } \\
\text { al. (2011) }\end{array}$ & $\begin{array}{l}\text { Brasil (1962-2010), Cointegração; } \\
\text { Função impulso-resposta; } \\
\text { Decomposição dos erros. }\end{array}$ & $\begin{array}{l}\text { i) elasticidades-renda são mais elevadas para } \\
\text { os bens de maiores intensidades tecnológicas; } \\
\text { ii) choque exógeno nas importações } \\
\text { apresentam um efeito reduzido sobre as } \\
\text { demais variáveis; iii) choques na taxa de de } \\
\text { câmbio real têm efeito significativo sobre as } \\
\text { importações; iv) choques sobre as exportações } \\
\text { têm efeitos pouco significativos sobre a renda } \\
\text { externa e a taxa de câmbio real. }\end{array}$ \\
\hline $\begin{array}{l}\text { Queiroz et } \\
\text { al. (2011) }\end{array}$ & $\begin{array}{l}\text { Brasil (1962-2008), Vetor } \\
\text { autoregressivo (VAR) e VEC }\end{array}$ & $\begin{array}{l}\text { i) o modelo mostrou-se um bom estimador do } \\
\text { crescimento real da economia; ii) no período } \\
\text { analisado, o processo de crescimento } \\
\text { brasileiro é restringido pelo balanço de } \\
\text { pagamentos; iii) no período analisado, não } \\
\text { foram observadas mudanças estruturais } \\
\text { relevantes no país. }\end{array}$ \\
\hline $\begin{array}{l}\text { Soares e } \\
\text { Teixeira } \\
\text { (2012) }\end{array}$ & $\begin{array}{l}\text { Brasil (1980-2011 (trimestral), } \\
\text { 1996-2010 (anual)), Cointegração } \\
\text { e VAR; mecanismo de correção } \\
\text { de erro; Dados em painel }\end{array}$ & $\begin{array}{l}\text { i) validade da LTM; ii) as elasticidades-renda } \\
\text { aumentam com o nível de intensidade } \\
\text { tecnológica; iii) na maioria dos casos é válida a } \\
\text { hipótese de exportações impulsionadas pelo } \\
\text { crescimento; iv) a estimação das elasticidades } \\
\text { setoriais tem papel relevante na compreensão } \\
\text { do padrão recente do desenvolvimento } \\
\text { brasileiro. }\end{array}$ \\
\hline $\begin{array}{c}\text { Romero, } \\
\text { Silveira e } \\
\text { Jayme (2011) }\end{array}$ & $\begin{array}{c}\text { Brasil (1962-2006), Cointegração } \\
\text { de Johansen }\end{array}$ & $\begin{array}{l}\text { i) dada as elasticidades setoriais, o crescimento } \\
\text { estimado apresentou um percurso semelhante } \\
\text { ao crescimento observado. }\end{array}$ \\
\hline $\begin{array}{l}\text { Gouvêa e } \\
\text { Lima (2010) }\end{array}$ & $\begin{array}{c}\text { Oito países latino-americanos e } \\
\text { asiáticos } \\
\text { (1962 a 2006), } \\
\text { Correção de erro vetorial }\end{array}$ & $\begin{array}{l}\text { i) o crescimento mostrou-se condicionado às } \\
\text { proporções setoriais das exportações e } \\
\text { importações; ii) as mudanças estruturais, que } \\
\text { inferem sobre a composição setorial da pauta } \\
\text { importadora e exportadora, inferem sobre o } \\
\text { crescimento. }\end{array}$ \\
\hline
\end{tabular}

Fonte: Elaborado pelo autor. 


\section{Metodologia}

No presente trabalho, as variáveis monetárias encontram-se em dólares (US\$) a preço de 2010. Os valores correspondentes às exportações e importações dos países de renda baixa foram extraídos do Common Format for Transient Data Exchange (COMTRADE), Revisão 2. A classificação dos bens em setores tecnológicos está de acordo com Lall (2000) que permite agregar os dados comerciais em consonância com o nível de complexidade tecnológica com base na mesma categoria de produto, Tabela $2^{5}$.

\section{Tabela 2. Classificação setorial}

\begin{tabular}{c|l}
\hline \multicolumn{1}{c}{ Classificação } & \multicolumn{1}{c}{ Exemplos } \\
\hline $\begin{array}{c}\text { Produtos primários } \\
\text { Recursos baseados em } \\
\text { manufatura }\end{array}$ & $\begin{array}{l}\text { Frutas frescas, carne, arroz, cacau, chá, café, madeira, } \\
\text { carvão, petróleo bruto, gás. } \\
\text { Carnes / frutas, bebidas, produtos de madeira, óleos } \\
\text { vegetais. } \\
\text { Concentrados de minério, petróleo / produtos de } \\
\text { borracha, cimento, pedras lapidadas, vidro. }\end{array}$ \\
Manufaturas de baixa tecnologia \\
$\begin{array}{c}\text { Tecidos têxteis, vestuário, chapelaria, calçado, } \\
\text { manufaturas de couro, artigos de viagem. } \\
\text { Cerâmica, peças / estruturas metálicas simples, joalharia, } \\
\text { brinquedos, produtos de plástico } \\
\text { intensidade tecnológica } \\
\text { Veículos de passageiros e peças, veículos comerciais, } \\
\text { motocicletas e peças. } \\
\text { Fibras sintéticas, produtos químicos e tintas, fertilizantes, } \\
\text { plásticos, ferro, tubos. } \\
\text { Motores, maquinaria industrial, bombas, comutadores, } \\
\text { navios, relógios. }\end{array}$ \\
$\begin{array}{l}\text { Office / processamento de dados / equipamento de } \\
\text { telecomunicações, Tr, transistores, } \\
\text { equipamentos de geração de energia. } \\
\text { Farmacêutica, aeroespacial, óptica / instrumentos de } \\
\text { medição, câmeras. }\end{array}$
\end{tabular}

Fonte: Adaptado de Lall (2000).

A classificação e composição das commodities segue o "IMF Primary Commodity Price Index" do Fundo Monetário internacional (FMI), Tabela 3. Os montantes exportados e importados também foram extraídos do COMTRADE e agrupados segundo a metodologia do FMI.

$\overline{{ }^{5} \text { Ver metodologia em Lall (2000). }}$ 
Tabela 3. Composição das commodities

\begin{tabular}{|c|c|c|}
\hline Tipo & Composição & Subcomposição \\
\hline Combustível & & Carvão, óleo cru, gás natural, propano \\
\hline \multirow{5}{*}{ Não-Combustível } & \multirow[b]{2}{*}{ Agricultura } & $\begin{array}{c}\text { Matérias-primas agrícolas (algodão, couro, } \\
\text { borracha, madeira, lã e fio) }\end{array}$ \\
\hline & & $\begin{array}{l}\text { Bebidas e Alimentos (Café, Cacau, Chá, Cereais, } \\
\text { Carne; Frutos do mar; Açúcar, Olho vegetal, frutas, } \\
\text { legumes, amendoim e nozes, produtos lácteos) }\end{array}$ \\
\hline & Fertilizantes & Nitrogênio, Fosfato, Potássio \\
\hline & \multirow[t]{2}{*}{ Metais } & $\begin{array}{c}\text { Metais básicos (alumínio, cobalto, cobre, minério } \\
\text { de ferro, chumbo, molibdênio, níquel, estanho, } \\
\text { urânio e zinco) }\end{array}$ \\
\hline & & Metais preciosos (ouro, prata, paládio, platina) \\
\hline
\end{tabular}

Fonte: Adaptado de FMI (2019).

As demais variáveis utilizadas: Produto Interno Bruto dos países analisados e a taxa de câmbio real, ambas extraídas da base do World Bank on World Development Indicators. Vale ressaltar que a taxa de câmbio apresentada foi obtida a partir do produto da taxa de câmbio oficial média (moeda local/dólares) e a razão entre o Índice de Preço ao Atacado dos Estados Unidos e o Índice de Preço ao Consumidor local, tendo como base o ano de 2010 para os índices de preços. Sendo assim, a expressão que representa a taxa de câmbio abordada no trabalho pode ser obtida como: $p_{U S \$, t}+e-p_{i t}{ }^{6}$.

A Tabela 4 apresenta a descrição das variáveis do modelo e os sinais esperados das estimativas. $\bigcirc$ modelo é replicado cinco vezes para as exportações e para as importações segundo o nível tecnológico considerado: produtos primários (PP), recursos baseados em manufatura $(\mathrm{RB})$, baixa intensidade tecnológica (LT), média intensidade tecnológica (MT) e alta intensidade tecnológica (HT). Observa-se que para as variáveis - exportações, importações, renda per capita doméstica, renda per capita do resto do mundo - o sinal esperado é positivo, assim como a taxa real de câmbio é positiva para as exportações, mas negativa para as importações.

\footnotetext{
${ }^{6}$ A construção da taxa de câmbio real segue o procedimento metodológico de Locatelli e Silva (1991) e Bassos (2014). Em suma, os autores sugerem que se relacionem os preços domésticos com os bens comercializáveis. Desta forma, a taxa de câmbio real permite captar a competitividade dos tradables diante dos preços domésticos e, desta forma, os ajustamentos de médio e longo prazo mediante variações na razão dos preços. Esta é a justificativa para se tomar o IPA dos Estados Unidos como proxy do índice de preços externos para tradables e o IPC da unidade de observação como o índice de preço doméstico. A literatura acadêmica apresenta alternativas para a construção do câmbio real que capta a diferença relativa entre os setores (ver McCombie, 2015).
} 
Tabela 4. Descrição das variáveis do modelo

A amostra é composta por 19 países de baixa renda para os quais se dispõe dados. A seleção respeita o critério do Rendimento Nacional Bruto per capita do Banco Mundial7 , tomando o ano de 20148, no qual considera países de baixa renda, aqueles cujo rendimento nacional bruto per capita é de $\$ 1.045$ ou menos: Afeganistão (AFG), Benin (BEN), Burquina Faso (BFA), Burundi (BDI), Camboja (KHM), República Central Africana (CAF), Comores (COM), Etiópia (ETH), Gâmbia (GMB), Madagascar (MDG), Malaui (MWI), Mali (MLI), Moçambique (MOZ), Nepal (NPL), Níger (NER), Tanzânia (TZA), Togo (TGO), Uganda (UGA), Zimbábue (ZWE).

\subsection{Metodologia de dados em painel}

Utilizar o modelo de estimação por meio de Dados em Painel consiste no uso combinado de séries de tempo (time-series) com cortes seccionais (cross-sections) que possibilita controlar as características não observáveis da variável estudada e corrigir os problemas das variáveis omitidas (Wooldridge, 2002).

O modelo contém, a partir de sua formulação originária, $\mathrm{K} \times \mathrm{N} \times \mathrm{T}$ coeficientes de regressão (Baum, 2006), sendo que o subscrito i representa as

\footnotetext{
${ }^{7}$ Ver a metodologia de classificação do Banco Mundial: http://data.worldbank.org/about/countryand-lending-groups. Do total de trinta e um países de renda baixa, foram excluídos das análises aqueles com indisponibilidade de dados tanto referente à renda, quanto às exportações e importações desagregadas segundo Lall (2000).

8 Cabe ressaltar que países como Sudão do Sul e Zimbábue, nos anos iniciais da amostra, encontravam-se no patamar de renda média, porém, em 2014, dos decréscimos no Rendimento Nacional Bruto per capita, estes países passaram a compor o grupo de países de renda baixa.
} 
unidades de observação e o subscrito t indica o período de tempo correspondente. modelo pode ser representado da seguinte forma

$$
y_{i t}=\sum_{k=1}^{k} x_{k i t} \beta_{k i t}+\epsilon_{i t}, i=1, \ldots, N, i=1, \ldots, T
$$

Onde: N é o número de observações (países de renda baixa); T é o número de períodos (ano); $\varepsilon_{i t}$ é o termo de erro; $\beta_{\text {kit }}$ representa os valores dos parâmetros a serem estimados e $x_{\text {kit }}$ representa os valores observados das variáveis independentes selecionadas para análise.

Este trabalho utilizará a estimação em GMM-Sistema, que consiste, basicamente, em desenvolver o modelo tomando suas primeiras diferenças; na Equação 18, o problema da endogeneidade do modelo é resolvido ao eliminar o termo de erro individual. Por outro lado, de acordo com Baltagi (2005), surgem dois outros problemas: a persistência da endogeneidade em $\Delta Y_{i t-1}=\left(Y_{i t-1}-Y_{i t-2}\right)$ e $u_{i t-1}$; e a autocorrelação dos erros pelo seu componente defasado, $u_{i t-1}$, dado que: $\Delta u_{i t}=u_{i t}-u_{i t-1}$ e $\Delta u_{i t-1}=u_{i t-1}-u_{i t-1}$.

O primeiro problema pode resolvido a partir do uso de variáveis instrumentais pertinentes para $\Delta Y_{i t-1}$; e o segundo a partir do uso do estimador GMM, que além de utilizar as variáveis instrumentais ainda considera a autocorrelação residual, o que permite aumentar a eficiência dos estimadores.

Portanto, tendo em vista a existência de endogeneidade entre as variáveis, as estimativas serão pelo Método dos Momentos Generalizado para Sistema (GMMSistema). Desta forma, como destaca Baltagi (2005), o estimador GMM-Sistema, Estimador Arellano-Bover (1995) / Blundell-Bond (1998), consiste em um sistema de equações. A equação diferenciada é instrumentalizada pelas defasagens dos níveis das variáveis como proposto em Arellano e Bond (1991) e a equação em nível é instrumentalizada pelas defasagens das diferenças. $\bigcirc$ Estimador GMM-Sistema admite o pressuposto de que a primeira diferença das variáveis explicativas não seja correlacionada com os efeitos fixos, os instrumentos utilizados sejam válidos e que os erros não tenham correlação serial de segunda ordem.

Apresentado o estimador a ser utilizado e tendo em vista a Equação 17, que representa a LTM, as estimativas a serem geradas tendem a indicar que a elasticidade da demanda por importações apresenta valor negativo, e a das exportações, valor positivo. As elasticidades são dadas pelo coeficiente que mensura a participação de cada setor no total das exportações e das importações. 
Para o cálculo da taxa de crescimento dada pela restrição externa são necessárias as taxas de crescimento da unidade de observação e do resto do mundo, que são observadas e dadas pelas bases de dados utilizadas e; pelas elasticidades renda das exportações e importações que serão estimadas pelo método de dados em painel. Tendo isto em vista, as equações abaixo são referentes às funções de demanda por exportações e importações, respectivamente:

$$
\begin{aligned}
& \Delta \ln \left[X_{j i t}\right]=\beta_{1} \Delta \ln \left[X_{i t-1}\right]+\beta_{2} \Delta \ln \left[P I B^{\prime}{ }_{i t}\right]+\beta_{3} \Delta \ln \left[\left(p_{U S \$}+e_{U S \$}-p_{j}\right)\right]+\mu_{j i t} \\
& \Delta \ln \left[M_{j i t}\right]=\beta_{4} \Delta \ln \left[M_{i t-1}\right]+\beta_{5} \Delta \ln \left[P I B_{i t}\right]+\beta_{6} \Delta \ln \left[\left(p_{U S \$}+e_{U S \$}-p_{j}\right)\right]+\mu_{J i t}
\end{aligned}
$$

Onde: o subscrito i representa as unidades de observação: países de renda média; o subscrito t é o período observado: $t=2000,2001, \ldots, 2013$; o subscrito j são os setores de intensidade tecnológica de acordo com a classificação de Lall (2000):

$j=1$ para bens primários (PP), $j=2$ para bens manufaturados (RB), $j=3$ para bens manufaturados de baixa intensidade tecnológica (LT), $j=4$ para bens manufaturados de média intensidade tecnológica (MT) e, $j=5$ bens manufaturados de alta intensidade tecnológica (HT). Os parâmetros $\beta_{1}, \beta_{2}, \beta_{3}, \beta_{4}, \beta_{5}$ e $\beta_{6}$ a serem estimados para cada setor j são, respectivamente, a variável explicativa defasada em um período das exportações, as elasticidades renda e preço da demanda por exportações, a variável explicativa defasada em um período das importações e, as elasticidades renda e preço da demanda por importações ${ }^{9}$.

\section{Resultados}

O rendimento per capita da amostra apresenta uma média de US\$530,34 com desvio padrão de US $\$ 369,41$. A evolução desta variável entre o primeiro e o último período, que se dispõe de dados para cada unidade de observação, permite classificar os países em três grupos. $\bigcirc$ primeiro grupo engloba os países que elevaram a renda per capita num valor superior à $15 \%$, onde situam quatorze deles, com destaque para Etiópia, Camboja e Moçambique. O segundo grupo é o dos países cuja renda variou positivamente e menos de 3\%: Togo, Burundi. E o terceiro grupo, composto por cinco países, que apresentou decréscimo da renda: Comoros (-3,69), Madagascar (5,04), Sudão do Sul (-8,49\%), Zimbabué (-32,21\%) e República Central Africana ($31,5 \%)$. Trata-se de países com estrutura produtiva relativamente simples, do ponto de vista tecnológico, e com importante participação no comércio de commodities,

\footnotetext{
${ }^{9}$ Cabe destacar que os dados para os preços setoriais não estão disponíveis e a taxa global de câmbio real foi utilizada como proxy para as taxas de câmbio reais setoriais.
} 
logo, o preço internacional delas tem relevância na avaliação da restrição externa (Eichengreen, Park e Shin, 2013; Bassos, 2014; Batista e Neder, 2020).

Os preços internacionais das commodities, partindo de 1980, não têm uma tendência clara até o início dos anos 2000. Apesar da oscilação para certos grupos de agregação (Gráfico 1), os preços passam a registrar valor ascendente até a crise econômica internacional de 2008/2009, quando voltam a oscilar positivamente até 2014 (Veríssimo e Xavier, 2013; Brandão, 2011).

\section{Gráfico 1. Índice de preços internacionais de commodities}

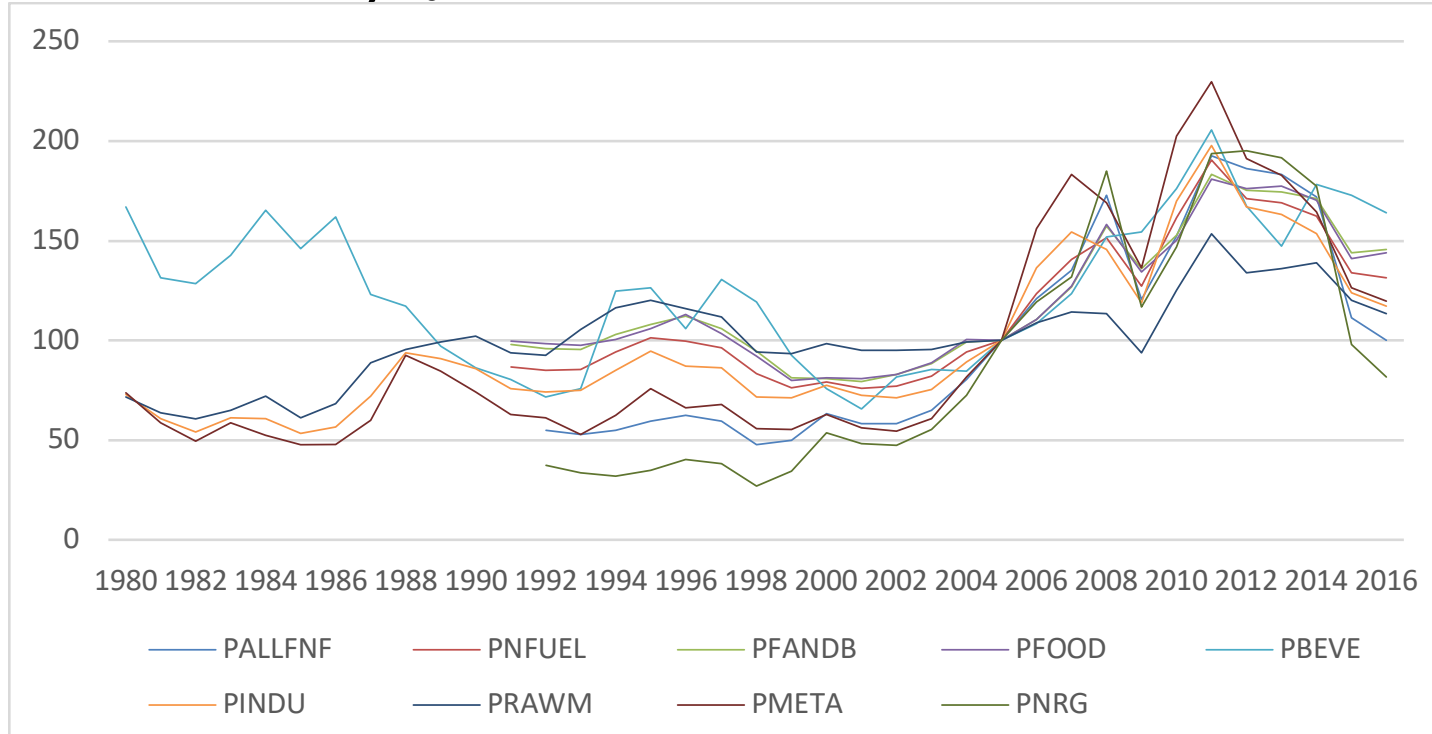

Nota: O valor observado em cada ano diz respeito a sua média mensal, expresso em US\$ com valor real referente ao ano de 2005. PALLFNF: todos os índices de preços de commodities (inclusive índices de preços de combustível e não-combustível); PNFUEL: índice de preços de não-combustíveis (inclui índices de preços de alimentos, bebidas e insumos industriais); PFANDB: índice de preços de alimentos e bebidas; PFOOD: índice de preços de alimentos; PBEVE: Índice de Preços de Bebidas; PINDU: índice de preços de insumos industriais; PRAWM: índice de matérias-primas agrícolas; PMETA: índice de preços de metais; PNRG: índice de combustível - Energia (inclui os índices de preço do petróleo bruto, gás natural e carvão). Fonte: Elaboração dos autores a partir dos dados do FMI.

Nos países de renda baixa, as commodities responderam pela média 32,48\% das exportações e 33,84\% das importações. Os Gráficos 2 e 3 apresentam essa participação, onde: NRG são as commodities combustíveis, RAWM é a matériaprima agrícola, FANDB são bebidas e alimentos, INDU são os fertilizantes, META são os metais e ALLFNF são todos os índices de preços de commodities.

Como pode-se observar, o grupo de alimentos e bebidas é o principal a ser exportado. Apesar da oscilação decrescente no período analisado, o valor exportado deste grupo aumentou, porém menos do que o total exportado. Com exceção dos fertilizantes, as demais commodities também são relativamente importantes na pauta exportadora da amostra por responderem por mais de 5\% do total exportado.

Do ponto de vista das importações, os combustíveis se destacam entre as demais commodities, respondendo pela média de 16,51\% do total importado no 
período analisado. No ponto intermediário, tem-se a importação por matéria-prima agrícola e bebidas e alimentos.

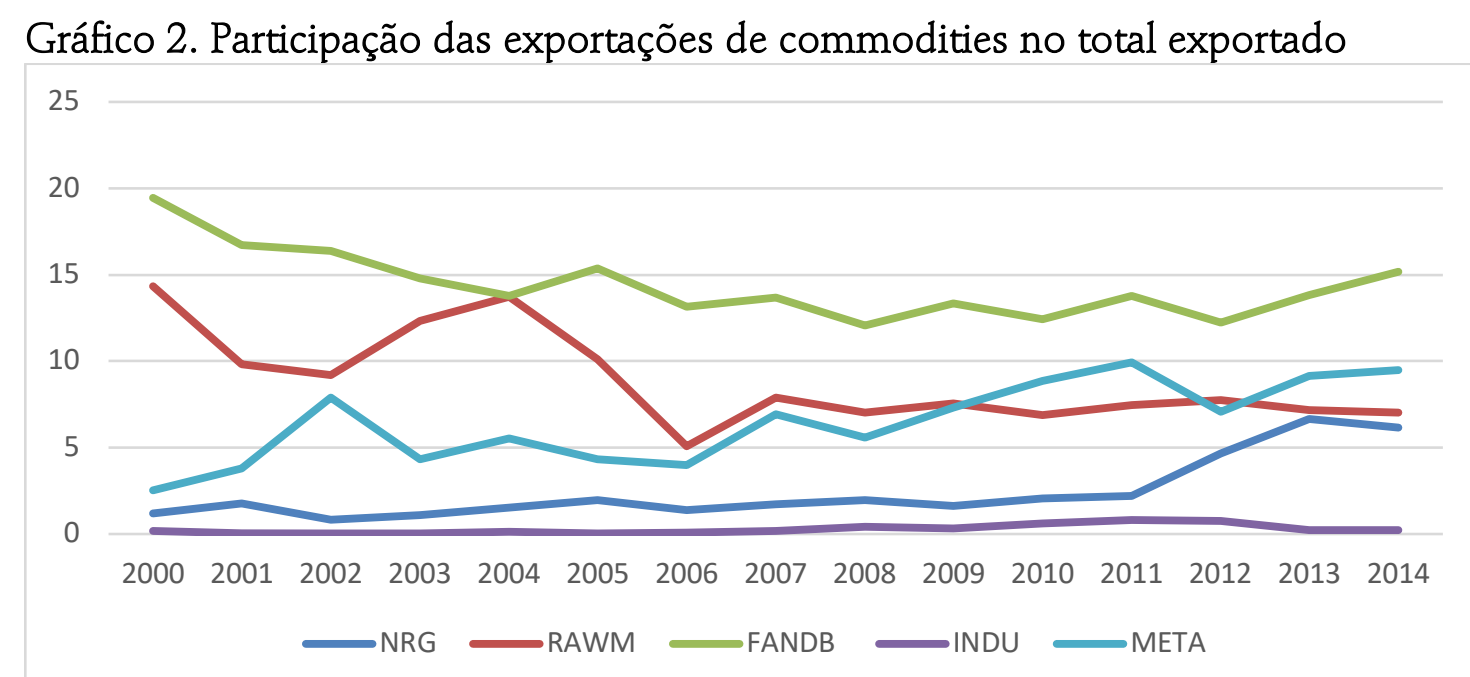

Fonte: Elaboração dos autores a partir dos dados do FMI e do COMTRADE.

\section{Gráfico 3. Participação das importações de commodities no total importado}

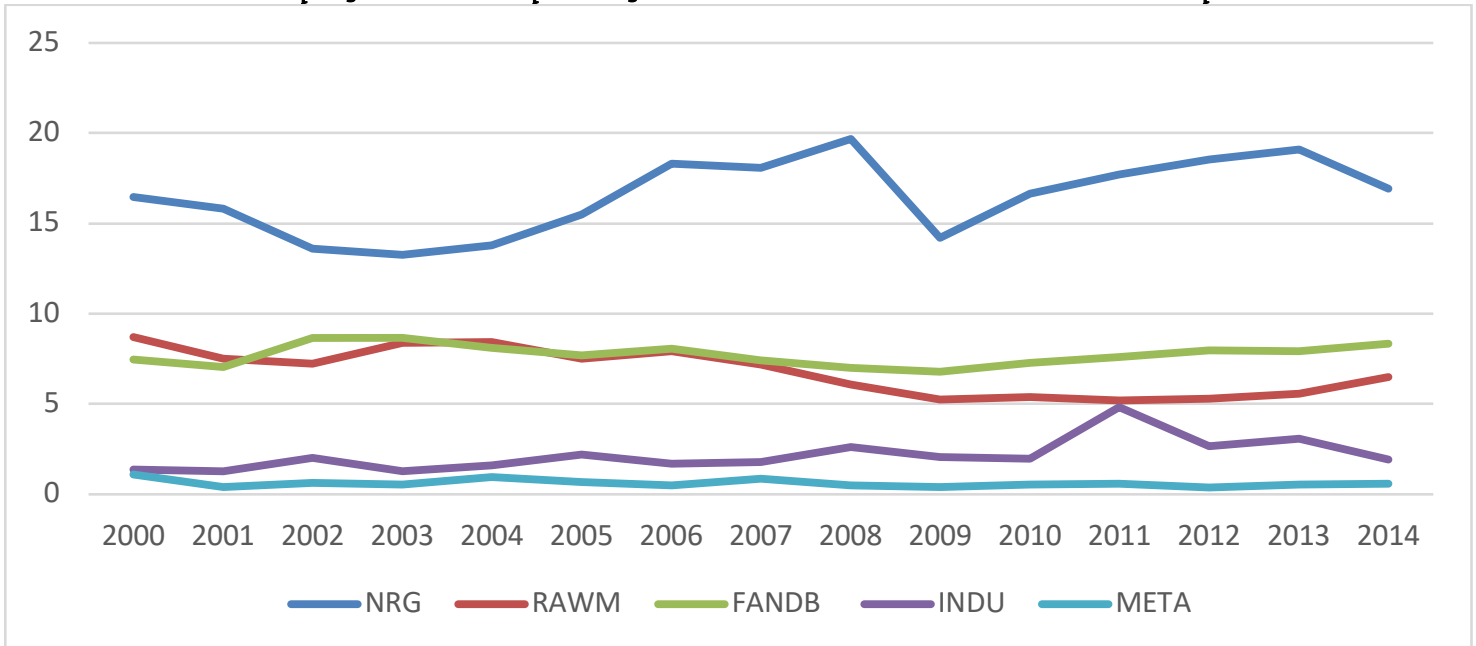

Fonte: Elaboração dos autores a partir dos dados do FMI e do COMTRADE.

Nota-se que o saldo comercial acumulado é negativo e crescente entre as commodities combustível (Tabela 3), ilustrando a crescente dependência externa destes bens. Matéria-prima agrícola e fertilizantes também apresentaram déficit comercial em todo o período analisado. A produção de alimentos e bebidas tem uma inflexão no ano de 2007 quando passa de um saldo positivo para negativo, e ressaltase que, nos anos seguintes, este déficit tende a ser crescente. Somente as commodities de metais apresentam superávit que, inclusive, tem tendência crescente. Porém, quando analisado de forma agregada, os superávits em META e em FANDB, no intervalo de 2000-2007, não são suficientes para cobrir os déficits observados nas demais desagregações das commodities; no período analisado, o déficit no comércio de commodities elevou em mais de 574\%. 
Tabela 5. Saldo comercial por composição das commodities

\begin{tabular}{c|cccccc}
\hline & NRG & RAWM & FANDB & INDU & META & ALLFNF \\
\hline 2000 & -25.917 & -0.986 & 5.792 & -2.126 & 0.544 & -22.692 \\
2001 & -22.128 & -2.513 & 4.217 & -1.874 & 2.764 & -19.533 \\
2002 & -20.896 & -1.942 & 3.369 & -3.162 & 7.261 & -15.370 \\
2003 & -25.995 & -1.982 & 0.558 & -2.598 & 4.235 & -25.782 \\
2004 & -29.924 & 0.731 & 1.572 & -3.519 & 6.026 & -25.114 \\
2005 & -39.025 & -5.171 & 2.224 & -5.871 & 4.670 & -43.173 \\
2006 & -24.498 & -12.632 & 3.553 & -4.707 & 6.755 & -31.530 \\
2007 & -65.359 & -12.167 & -2.191 & -6.426 & 9.821 & -76.322 \\
2008 & -91.561 & -14.612 & -8.256 & -11.768 & 9.628 & -116.569 \\
2009 & -66.071 & -10.101 & -5.642 & -9.453 & 12.976 & -78.291 \\
2010 & -92.156 & -13.845 & -10.518 & -9.902 & 19.784 & -106.638 \\
2011 & -116.600 & -11.879 & -7.984 & -31.077 & 28.533 & -138.931 \\
2012 & -122.400 & -13.096 & -17.810 & -17.272 & 21.261 & -149.267 \\
2013 & -127.930 & -20.391 & -17.261 & -23.368 & 25.410 & -163.543 \\
2014 & -119.520 & -29.726 & -16.587 & -15.214 & 27.993 & -153.055 \\
\hline$\Delta \%$ & 361.170 & 2916.320 & -386.380 & 615.730 & 5044.880 & 574.483 \\
\hline
\end{tabular}

Nota: Em 100 milhões de dólares. Fonte: Elaboração dos autores a partir dos dados do FMI e do COMTRADE.

Ou seja, apesar de a estrutura produtiva, relativamente carente de conteúdo tecnológico, e da parcela importante das exportações restringirem-se em commodities, os países que compõem a amostra deste trabalho também são demandantes daquela gama de commodities de que são exportadores. Isso faz diluir os ganhos, em termos de preços, do volume exportado que, consequentemente, compromete o crescimento tal como argumentado no referencial teórico.

Descritas essas especificidades estruturais da amostra, nos resultados das estimativas, nas Tabelas 6 e 7, o teste de Arellano-Bond (ar1p) corresponde ao teste de autocorrelação de Arellano-Bond para a correlação de primeira ordem para as diferenças dos erros do modelo; da mesma forma, Arellano \& Bond (ar2p) é o teste de autocorrelação de Arellano-Bond para a correlação de segunda ordem para as diferenças dos erros do modelo. Os valores dos testes Arellano-Bond (ar1p), Arellano-Bond (ar2p) e do Teste Hansen se referem aos p-valores correspondentes às estatísticas de teste.

As funções de demanda por exportações e importações setoriais, estimadas a partir das Equações 7 e 8, são os parâmetros para estimar a LTM. Pelas Tabelas abaixo, todas as elasticidades renda, exportação e importação apresentaram o sinal esperado; e as elasticidades-preço não apresentaram significância estatística. Além disso, a variável dependente defasada, para os casos que demonstrou significância 
estatística e, consequentemente, permitiu captar o efeito dinâmico do modelo, foi inelástica. Somente para o setor de baixa tecnologia, nas importações, que a variável dependente defasada teve significância estatística e sinal negativo, indicando a redução na quantidade importada neste setor, dado o volume importado no período anterior.

A Tabela 6 indica que as exportações de todos os setores são elásticas à renda, além disto, os setores de maior intensidade tecnológica apresentam maior elasticidade-renda. Na Tabela 7, a elasticidade-renda das importações é inelástica somente para o setor de produtos primários, indicando que a elevação de $10 \%$ da renda doméstica leva à ampliação em 6,87\% da importação de produtos primários. Os setores de maiores elasticidades-renda das importações foram observados nos setores de baixa e alta intensidade tecnológica, respectivamente.

Tabela 6. Elasticidade-renda e preço setorial das exportações

\begin{tabular}{|c|c|c|c|c|c|}
\hline & $\mathrm{PP}$ & $\overline{R B}$ & LT & MT & HT \\
\hline$\Delta \ln \left[X_{i t-1}\right]$ & $\begin{array}{l}0.301^{* *} \\
(0.132)\end{array}$ & $\begin{array}{c}0.583^{\text {*** }} \\
(0.160)\end{array}$ & $\begin{array}{c}0.368 \\
(0.243)\end{array}$ & $\begin{array}{c}0.337^{*} \\
(0.164)\end{array}$ & $\begin{array}{c}0.343 \\
(0.236)\end{array}$ \\
\hline$\Delta \ln \left[P I B \_p c^{\prime}{ }_{i t}\right]$ & $\begin{array}{l}1.354^{*} \\
(0.699)\end{array}$ & $\begin{array}{l}1.281^{*} \\
(0.718)\end{array}$ & $\begin{array}{l}1.016^{* *} \\
(0.363)\end{array}$ & $\begin{array}{c}2.317^{* * *} \\
(0.649)\end{array}$ & $\begin{array}{l}2.079^{*} \\
(1.234)\end{array}$ \\
\hline$\Delta \ln [$ câmbio] & $\begin{array}{c}0.134 \\
(0.697)\end{array}$ & $\begin{array}{c}0.292 \\
(0.318)\end{array}$ & $\begin{array}{c}0.148 \\
(0.346)\end{array}$ & $\begin{array}{l}-0.620 \\
(0.793)\end{array}$ & $\begin{array}{l}-0.424 \\
(0.586)\end{array}$ \\
\hline Constante & $\begin{array}{l}104.241^{*} \\
(56.486)\end{array}$ & $\begin{array}{r}-12.646^{*} \\
(6.627)\end{array}$ & $\begin{array}{c}-9.646^{* *} \\
(4.294)\end{array}$ & $\begin{array}{c}-16.760^{* *} \\
(7.050)\end{array}$ & $\begin{array}{l}-16.843 \\
(13.180) \\
\end{array}$ \\
\hline Observações & 234 & 229 & 230 & 224 & 224 \\
\hline $\mathrm{n}^{\circ}$ instrument & 70 & 22 & 50 & 32 & 35 \\
\hline$(\operatorname{ar1p})$ & 0.047 & 0.058 & 0.013 & 0.031 & 0.059 \\
\hline$(\operatorname{ar} 2 \mathrm{p})$ & 0.773 & 0.359 & 0.121 & 0.213 & 0.779 \\
\hline Teste Hansen & 1.000 & 0.440 & 1.000 & 0.989 & 0.994 \\
\hline
\end{tabular}

Tabela 7. Elasticidade renda e preço setorial das importações

\begin{tabular}{cccccc}
\hline & $\mathrm{PP}$ & $\mathrm{RB}$ & $\mathrm{LT}$ & $\mathrm{MT}$ & $\mathrm{HT}$ \\
\hline$\Delta \ln \left[M_{i t-1}\right]$ & $0.605^{* * *}$ & $0.210^{*}$ & $-0.323^{* *}$ & $0.460^{* *}$ & -0.051 \\
& $(0.150)$ & $(0.110)$ & $(0.138)$ & $(0.173)$ & $(0.245)$ \\
$\Delta \ln \left[P I B \_p c_{i t}\right]$ & $0.687^{* * *}$ & $1.325^{* * *}$ & $4.029^{* * *}$ & $1.487^{* *}$ & $3.075^{* * *}$ \\
& $(0.169)$ & $(0.386)$ & $(1.127)$ & $(0.601)$ & $(1.114)$ \\
$\Delta \ln [$ câmbio $]$ & 0.083 & 0.300 & 1.567 & 0.049 & 0.0936 \\
& $(0.238)$ & $(0.347)$ & $(1.342)$ & $(0.232)$ & $(0.601)$ \\
Constante & $-3.736^{*}$ & $-7.119^{*}$ & $-30.673^{* *}$ & $-7.610^{* *}$ & $-17.122^{*}$ \\
& $(1.902)$ & $(4.051)$ & $(13.497)$ & $(3.622)$ & $(9.869)$ \\
\hline Observações & 232 & 232 & 234 & 234 & 234 \\
$\mathrm{n}^{\circ}$ instrument & 54 & 67 & 16 & 31 & 15 \\
\hline (ar1p) & 0.016 & 0.007 & 0.385 & 0.257 & 0.340 \\
(ar2p) & 0.485 & 0.322 & 0.400 & 0.397 & 0.809 \\
Teste Hansen & 1.000 & 1.000 & 0.669 & 0.833 & 0.184 \\
\hline
\end{tabular}

Notas: Os valores entre parênteses são os erros padrões robustos. ${ }^{* * *} p<0,01,{ }^{* *} p<0,05,{ }^{*} p<0,1$

Fonte: Elaboração dos autores a partir dos dados do COMTRADE e do World Development Indicators do World Bank. 
Das elasticidades estimadas, a literatura indica dois testes para testar a validade da LTM: o primeiro, de McCombie (1989), estabelece um paralelo entre a taxa de crescimento efetiva e a calculada a partir das elasticidades estimadas; e o segundo, de acordo com Thirlwall (2005), é comumente utilizado para amostras de países, o qual gera uma regressão com a variação da renda per capita observada enquanto variável dependente e a renda dada pela LTM como variável independente:

$$
P I B \_p c_{\text {observado }}=\beta_{0}+\beta_{1} P I B_{-} p c_{\text {estimado }}+u 10
$$

A Tabela 8, referente ao primeiro teste, apresenta a proximidade entre as duas taxas de variação da renda, com erro de previsão de $2,84 \%$. A validação da LTM é dada pelo teste t-Student, visto que a igualdade entre ambas as taxas não pode ser rejeitada. Portanto, corrobora-se a hipótese de que a variação da renda da amostra de países de renda baixa (2000-2014), está associada à disponibilidade de divisas.

Tabela 8. Taxas de crescimento per capita: LTM e efetiva

\begin{tabular}{lcc}
\hline & LTM & Efetiva \\
\hline Crescimento 2000-2014 (\%) & 36,369 & 39,218 \\
Erro & 2,849 & \\
Estatística t-Student & 0.114 & \\
Fonte: Elaboração dos autores. & &
\end{tabular}

Cabe observar que quando cruzadas as commodities com a gama de produtos segundo a classificação tecnológica, observa-se que elas estão majoritariamente inseridas como produtos primários e recursos baseados em manufatura (PP e RB). Tomando '_x' para se referir às exportações e '_m' às importações, nos gráficos abaixo, pode-se notar a participação relativamente elevada de PP e RB ${ }^{11}$ nas exportações e importações. Consequentemente, a elevação dos preços das commodities tem seu efeito reduzido sobre o crescimento por se concentrar nos setores de menores elasticidades-renda e por estes preços incidirem sobre uma parcela considerável das importações.

\footnotetext{
${ }^{10}$ Estimar as elasticidades renda por GMM-Sistema nos fornece os valores para o período considerado (2000-2014) e a renda estimada pela LTM para este período. Foi calculado, portanto, a variação da renda entre 2000 e 2014. Isto inviabiliza o segundo teste ao estimar a regressão $y_{\text {observado }}=\beta_{0}+$ $\beta_{1} y_{\text {estimado }}+u$, pois apesar de os dados disponíveis oferecerem informações para a renda observada entre 2000-2014, dadas as estimativas, dispomos de apenas duas amostras para a renda estimada: 2000 e 2014; e dois parâmetros: $\beta_{0}$ e $\beta_{1}$.

11 Devido às restrições do número de páginas e visando a objetividade na exposição dos resultados, a desagregação da composição da pauta exportadora e importadora entre os países é inviável de ser apresentada. Todavia, caso tenha interesse nos dados, entre em contato com os autores. Salvo poucas exceções e de forma desagregada entre as unidades de observação, as exportações da amostra são concentradas em PP, RB e LT, enquanto as importações são mais distribuídas com participação relativamente mais elevada para RB e MT, sem outliers a serem destacados. É baseado nesta constatação que, para as estimações e painel de dados, os países foram considerados como parte de um todo, ou seja, tomados enquanto unidades de observação. Portanto, as elasticidades deverão ser interpretadas como caso geral da amostra.
} 
Gráfico 4. Exportações setoriais (\%): 2000-2014

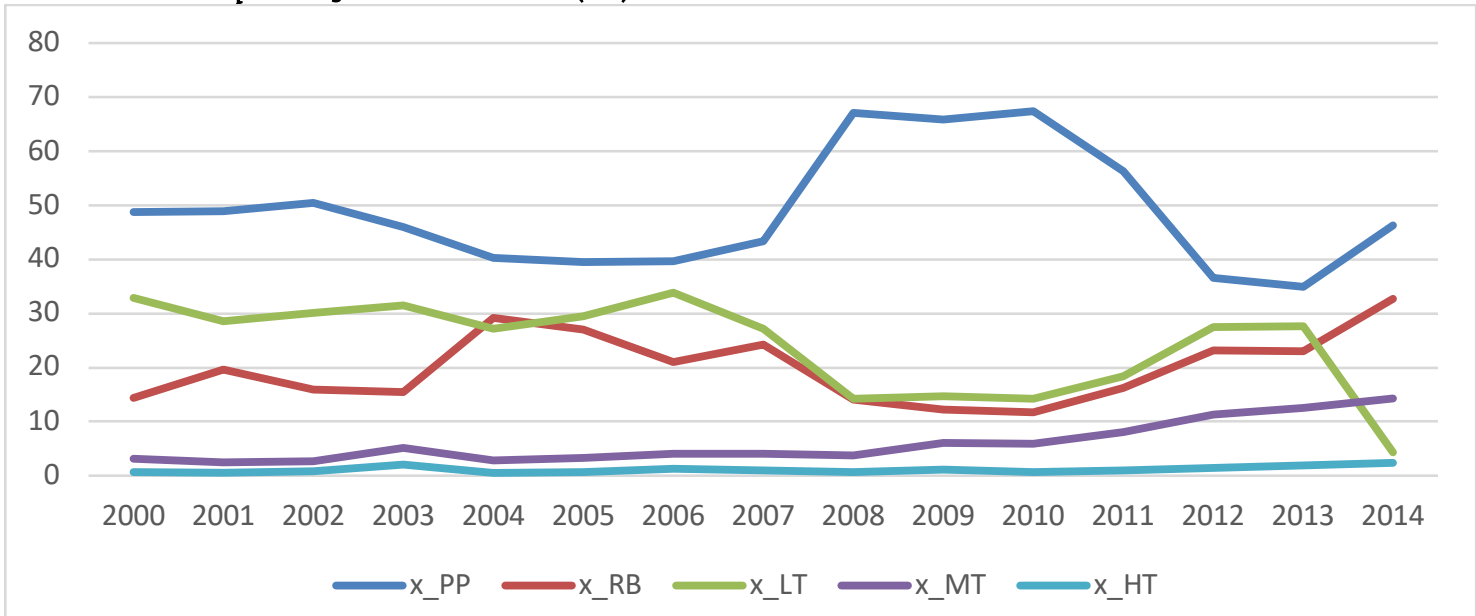

Fonte: Elaboração dos autores a partir dos dados do COMTRADE e do World Development Indicators do World.

\section{Gráfico 5. Importações setoriais (\%): 2000-2014}

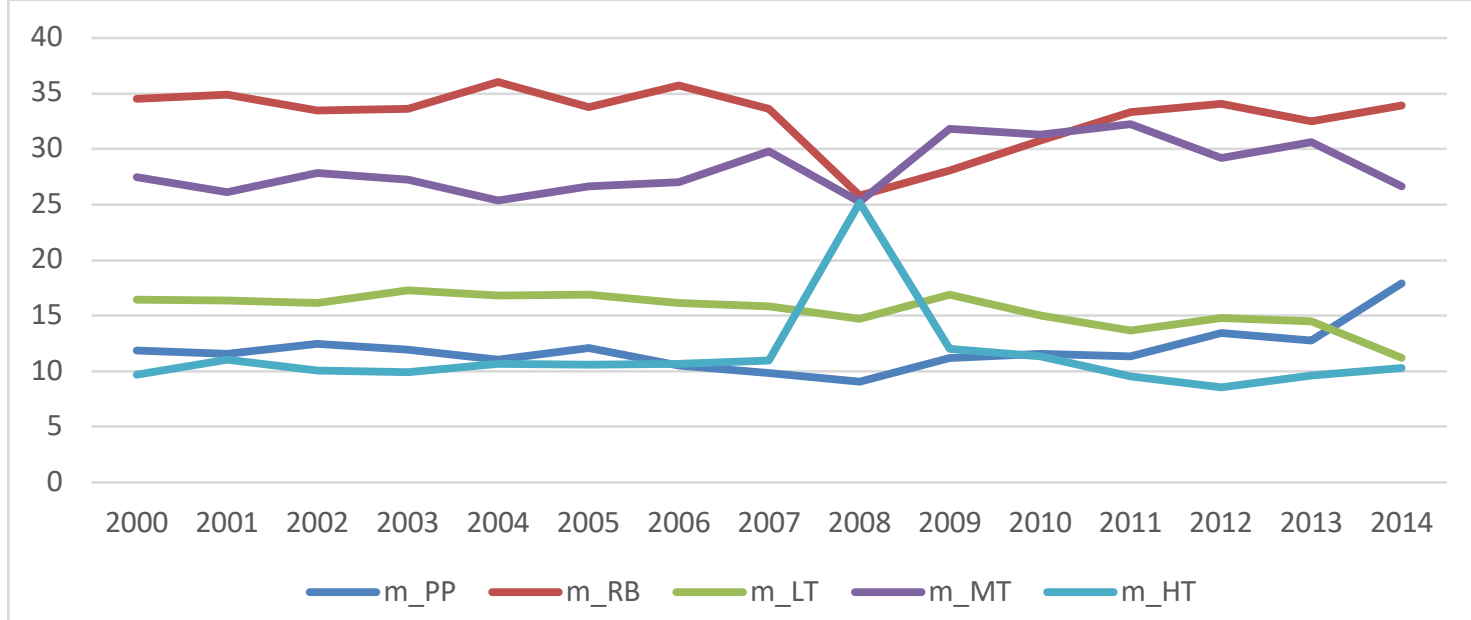

Fonte: Elaboração dos autores a partir dos dados do COMTRADE e do World Development Indicators do World Bank.

Estendendo o paralelo entre o percentual setorial do comércio externo com as elasticidades-renda ${ }^{12}$, constata-se a elevação da participação das exportações do setor de recursos baseados em manufatura em detrimento do setor de baixa tecnologia, além da baixa participação do setor de alta intensidade tecnológica. Com exceção do pico da alta intensidade tecnológica em 2008, são os setores de recursos baseados em manufatura e média intensidade tecnológica que representam a maior parte das importações da amostra. Além disto, nota-se uma certa estabilidade destes valores importados.

12 Cabe destacar a redução brusca nas LT_x de 2013 para 2014 em virtude da ausência de dados das exportações setoriais do Camboja em 2014. Ele responde por uma parcela significativa das exportações de produtos de baixa intensidade tecnológica da amostra: 73,12\%. A menor participação foi em 2000, 58,70\%; e a maior em 2006, 85,46\%. 
Os setores com menores elasticidades-renda das exportações são x_PP, x_RB e x_LT, nos quais se concentram as exportações dos países de renda baixa. $O$ percentual exportado nestes três setores responde pela média de 91,91\% do total exportado no período 2000-2014. Consequentemente, as exportações dos setores de maior intensidade tecnológica, MT_x e HT_x, que são os de maior elasticidaderenda, tiveram participação média de $7,09 \%$ no período analisado. Isso permite corroborar a hipótese de que os países de renda baixa, dada a composição setorial das exportações, deixam de ganhar com os episódios de variação positiva do crescimento externo.

Observadas as elasticidades-renda das importações, destaca-se que a participação de cada setor no total importado pouco variou no período considerado. A maior parte das importações se concentra nos setores de recursos baseados em manufatura e de média intensidade tecnológica. Os setores com maiores elasticidades-renda, e baixa e alta intensidade tecnológica respondem pela média de $26,78 \%$ do total importado no período.

\section{Considerações finais}

Os testes e evidências indicam que, na amostra selecionada, as unidades de observação não se mostraram capazes de sustentar déficits crescentes no balanço de pagamentos e, portanto, o crescimento foi restringido - uma restrição possivelmente dada pelas elasticidades-renda das exportações e importações.

As elasticidades-renda das exportações, além de elásticas, mostraram-se mais sensíveis à variação da renda do resto do mundo para os setores de maior intensidade tecnológica, semelhante aos resultados apresentados na análise bibliográfica. Para as elasticidades-renda das importações, os setores de baixa e alta intensidade tecnológica são mais sensíveis à variação da renda interna. Quando se compara as elasticidades-renda estimadas com a composição da pauta exportadora, nota-se que os países de renda baixa não usufruem dos momentos de boom do crescimento externo, tendo em vista o baixo volume de exportações nos setores de maior elasticidade-renda. Para as importações, as evidências não apresentam tendência clara, porém o cruzamento indica um elevado volume de importações em setores elásticos.

Ademais, o boom nos preços das commodities não se mostrou suficiente para amortecer a restrição externa. A elevação desses preços se deu em setores com baixa elasticidade-renda e, além disso, os países que compõem a amostra também apresentam um volume considerável de importação de commodities. 
Em suma, os resultados encontrados indicam a necessidade de mudanças estruturais na composição tecnológica como instrumento de crescimento para essas economias analisadas. Ou seja, o debate em torno da composição setorial na literatura pós-Keynesiana, brevemente abordada neste trabalho, também é válida aos países de renda baixa, mesmo no contexto em que parte considerável dos seus exportados apresenta preços crescentes no mercado internacional.

\section{Referências}

Araujo, R.; Lima, G. (2007) "A structural economic dynamics approach to Balanceof-Payments-Constrained growth". Cambridge Journal of Economics 31(5), p. 755-774. https://doi.org/10.1093/cje/bem006

Arellano, M.; Bond, S. (1991) "Some tests of specification for Panel Data: Monte Carlo evidence and an application to employment equations". The Review of Economic Studies 58(2), p. 277-297. https://doi.org/10.2307/2297968

Arellano, M.; Bover, O (1995) "Another look at the instrumental variable estimation of Error-Components models". Journal of Econometrics 68(1), p. 29-51. https://doi.org/10.1016/0304-4076(94)01642-D

Baltagi, B. H (2005) "Econometric analysis of Panel Data Ba Ed.)". John Wiley \& Sons.

Bassos, M. C. (2014) "A economia brasileira sob restrição do balanço de pagamentos: uma análise empírica da Lei de Thirlwall no boom das commodities”. Anais do $42^{\circ}$ Encontro Nacional de Economia. Disponível em: https://en.anpec.org.br/previous-editions.php?r=encontro-2014, acesso em 20 de maio de 2019.

Batista, H. R.; Neder, H. D. (2020) "Crescimento sob restrição externa em países de renda média: uma análise empírica da Lei de Thirlwall Multisetorial no contexto de boom das commodities (2000-2013)". Estudios Económicos, 37(74), p. 127 160. https://doi.org/10.52292/j.estudecon.2020.1333

Baum, C. F. (2006) "An introduction to modern econometrics using Stata". TX: Stata Press. College Station.

Blecker, R. A.; Setterfield, M. (2019) "Heterodox macroeconomics: models of demand, distribution, and growth". Edward Elgar Publishing, 559p. 
Blundell, R.; Bond, S. (1998) "Initial Conditions and moment restrictions in dynamic Panel Data models". Journal of Econometrics 87(1), p. 115-143. https://doi.org/10.1016/S0304-4076(98)00009-8

Brandão, A. S. P. (2011) "Preços elevados de commodities". Revista de Política Agrícola, 20(1), p. 117-118.

Carbinato, D. D. A. (2010) "Crescimento econômico e estrutura produtiva no Brasil: análise das relações entre padrão setorial e restrição externa”. Anais do $3^{\circ}$ Encontro da Associação Keynesiana Brasileira, 1-18, São Paulo - SP. Disponível em: https://associacaokeynesianabrasileira.org/, acessado em 20 de dezembro de 2010.

Catela, E. Y. S.; Porcile, G. (2010) "Estrutura das exportações e crescimento econômico: uma análise empírica, 1985-2003". Economia e Sociedade 19(2), p. 291-313. https://doi.org/10.1590/S0104-06182010000200004

Cimoli, M., Porcile, G., Primi, A. e Vergara, S. (2005) "Cambio estructural, heterogeneidad productiva y tecnología en América Latina”. In: Cimoli, M. (eds) Heterogeneidad estructural, asimetrías tecnológicas y crecimiento en América Latina. CEPAL: 9-39.

Cimoli, M.; Porcile, G.; Rovira, S. (2010) "Structural change and the BOP-Constraint: why did Latin America fail to converge?", Cambridge Journal of Economics 34(2), p. 389-411. https://doi.org/10.1093/cje/ben060

COMTRADE (2017) "United Nations Commodity Trade Statistics Database COMTRADE". Statistics Division. Available at: http://comtrade.un.org/db/, acesso em 20 de março de 2017.

Da Silva, G. J. C.; Santos, J. F. C. e Baptista, L. N. (2017) "A Lei de Thirlwall Multissetorial com fluxos de capitais: uma análise do plano nacional de exportações (2015-2018) usando simulações computacionais". Revista de Economia Política 37(3), p. 636-655. https://doi.org/10.1590/010131572017v37n03a10

Dutt, A. (2015) "Thirlwall's Law and uneven development". Journal of Post Keynesian Economics 24(3), p. 367-390. https://doi.org/10.1080/01603477.2002.11490331

Eichengreen, B.; Park, D.; Shin, K. (2013) "Growth slowdowns redux: new evidence on the middle-income trap". National Bureau of Economic Research, Working Paper 18673, 54p. 
FMI (2019) "IMF Primary Commodity Price Index". Available at: https://www.imf.org/en/Research/commodity-prices, acesso 01 de julho de 2020.

Gouvêa, R. R. (2010) "Padrão de especialização produtiva e crescimento econômico sob restrição externa: uma análise empírica". Tese de Doutorado. Universidade de São Paulo, São Paulo -SP. Disponível em: https://teses.usp.br/teses/disponiveis///12/12140/tde-10052010-144501/ptbr.php, acesso em 20 de maio de 2018.

Gouvêa, R. R.; Lima, G. T. (2010) "Structural change, balance-of-payments constraint, and economic growth: evidence from the multisectoral Thirlwall's law". Journal of Post-Keynesian Economics, 33(1), p. 169-204. https://doi.org/10.2753/PKE0160-3477330109

Im, F. G.; Rosenblatt, D. (2013) "Middle-income traps: a conceptual and empirical survey". World Bank, Policy Research Working Paper n6594, 40p.

Lall, S. (2000) "The technological structure and performance of developing country manufactured exports, 1985-98". Oxford development studies 28(3), p. 337369. https://doi.org/10.1080/713688318

Locatelli, R. L.; Silva, J. A. B. (1991) "Câmbio real e competitividade das exportações brasileiras. Revista Brasileira de Economia." 45(4), p.543-564. Disponível em: http://bibliotecadigital.fgv.br/ojs/index.php/rbe/article/view/533, acesso em 20 de julho de 2019.

McCombie, J. S. L. (1989) "Thirlwall's Law' and balance of payments constrained growth - a comment on the debate." Applied Economics 21(5), p. 611-629. https://doi.org/10.1080/758524894

McCombie, J. S. L. (2011) "Criticisms and defenses of the balance-of-payments constrained growth model: some old, some new". PSL Quarterly Review 64(259), p. 353-392. https://doi.org/10.13133/2037-3643/9405

Pasinetti, L. (1981) "Structural change and economic growth - a theoretical essay on the dynamics of the Wealth of the Nations". Cambridge University Press, Cambridge-UK.

Pasinetti, L. (1993) "Structural economic dynamics - a theory of the economic consequences of human learning". Cambridge University Press, CambridgeUK. 
Queiroz, P. W. V.; Spolador, L. A.; Higachi, H. Y.; Castilho, M. L. (2011) "A Lei de Thirlwall Multissetorial: um teste empírico para a economia brasileira entre 1962-2008 e uma análise da estrutura produtiva nos governos Lula”. Anais do $14^{\circ}$ Encontro de Economia da Região Sul - Anpec Sul. Disponível em: http://www.anpec.org.br/novosite/br/xxiii-encontro-de-economia-da-regiaosul, acesso em 20 de julho de 2012.

Romero, J. P.; McCombie, J. S. L. (2016) “The Multi-Sectoral Thirlwall's Law: evidence from 14 developed European countries using product-level data". International Review of Applied Economics 30(3), p. 1 22. https://doi.org/10.1080/02692171.2015.1102207

Romero, J. P.; Silveira, F.; Jayme J. F. G. (2011) "Brazil: structural change and balanceof-payments constrained growth". CEPAL Review 2011(105), p. 173-195. https://doi.org/10.18356/e69bceca-en

Soares, C.; Teixeira, J. R. (2012) "A Lei de Thirlwall Multissetorial: novas evidências para o caso brasileiro". Anais do $40^{\circ}$ Encontro Nacional de Economia, Porto de Galinhas - PE. Disponível em: https://www.anpec.org.br/encontro/2012/inscricao/files_I/i50b65cbe90575a664c7fad6367e00372e.pdf, acesso em 20 de junho de 2019.

Thirlwall, A. P. (1979) "The balance of payments constraint as an explanation of international growth rates differences". PSL Quarterly Review 32(128), p. 4553. https://doi.org/10.13133/2037-3643/12804

Thirlwall, A. P. (2005) "A natureza do crescimento econômico: um referencial alternativo para compreender o desenho das nações". Ipea, Brasília - DF, 112p.

Thirlwall, A. P. (2011) "Balance of Payments constrained growth models: History and overview". PSL Quarterly Review 64(259), p. 307-351. https://doi.org/10.1057/9781137023957_2

Thirlwall, A. P.; Pacheco, P. L. (2008) "Trade liberalization and the poverty of nations". Edward Elgar, n 13089, 264p.

Tho, V. T. (2013) "The middle-income trap: issues for members of the Association of Southeast Asian Nations". Asian Development Bank Institute, Working Paper Series, n 421, 33p.

Verissimo, M. P.; Xavier, C. L. (2013) "Taxa de câmbio, exportações e crescimento: uma investigação sobre a hipótese de doença holandesa no Brasil". Revista de 
Economia Política, 33(1), p. 82-101. https://doi.org/10.1590/S010131572013000100005

Wooldridge, J. M (2002) "Econometric analysis of Cross Section and Panel Data". Cambridge: MIT Press. 